\title{
Training of SMEs for frozen food shelf life testing and novel smart packaging application for cold chain monitoring
}

\author{
Theofania Tsironi ${ }^{\mathrm{a}}$, Marianna Giannoglou $^{\mathrm{a}}$, Eleni Platakou $^{\mathrm{a}}$, And Petros \\ TAOUKIS $^{\mathrm{a}^{*}}$ \\ ${ }^{a}$ National Technical University of Athens, School of Chemical Engineering, Laboratory of Food Chemistry and \\ Technology, 5, Iroon Polytechniou, Zografou 15780, Athens, Greece \\ ${ }^{*}$ Corresponding author \\ taoukis@chemeng.ntua.gr \\ TEL: $+30-2107723171$ \\ FAX: $+30-2107723163$ \\ Received: 10 July 2014; Published online: 18 October 2015 \\ Invited paper from the $3^{\text {rd }}$ International ISEKI_Food Conference - ISEKI_Food 2014 - Bridging Training and \\ Research for Industry and the Wider Community - Food Science and Technology Excellence for a Sustainable \\ Bioeconomy
}

\begin{abstract}
Application of an optimized cold chain management system for frozen products can be assisted by monitoring with Time Temperature Integrators (TTI). TTI are smart labels that cumulatively show the product history in an easily measurable, time-temperature dependent change. In the IQ-Freshlabel European project enzymatic and photochromic TTI were developed and tested for frozen products. Further to the technical objectives, training activities were implemented to provide information and training to the staff of Small and Medium-sized Enterprises (SMEs) regarding the properties of the developed TTI and their utilization within food packaging, transport, storage and sale. In total, more than 276 European companies and consumers representing the frozen food industry, the packaging industry and food business operators were successfully trained. The objective of the present article is to describe a general methodology for frozen food shelf life testing and modelling, and the selection of appropriate TTI for specific foods. This document serves as a technical manual for SMEs, including a case study for frozen shrimp and application of enzymatic and photochromic TTI, aiming to build their capacities to understand and use TTI for frozen food products. The value of systematic modelling of the food quality kinetics as well as the response of the TTI in building an effective chill chain management system is also demonstrated. The TTI response study allows a reliable optimization and selection of TTI to be correlated to the target food product for which accurate information on temperature dependence is available.
\end{abstract}

Keywords: Cold chain; Frozen food; Shelf life; Smart packaging; Time temperature indicators

\section{Introduction}

Continuous monitoring and verification of the shelf life of food products is necessary and requires the development of practical systems that can monitor, record and translate the temperature effect of food quality from production to consumption. According to the Regulation (EU) No 1169/2011, "date of minimum durability of a food means the date until which the food retains its specific properties when properly stored". The food business operators are responsible for shelf life determination for a specific food product un- 
der defined storage conditions in the temperature range of the real cold chain.

It is well known that the quality of the food product that reaches the consumer would have deteriorated during transportation and storage compared to the quality characteristics at the time of production (Fu \& Labuza, 1997; Gates, Eudaly, Parker, \& Pittman, 1985). Temperature data from recent surveys showed that, despite good practices, monitoring and control efforts, significant temperature fluctuations are observed during distribution, retail and domestic storage. More specifically, $40 \%$ of the total time of the profile temperatures of frozen fish products are over the recommended temperature, varying between $-16^{\circ} \mathrm{C}$ and $-12^{\circ} \mathrm{C}$ (Source: European Cold Chain Database-FRISBEE project, http://www. frisbee-project.eu/coldchaindb.html). Quality changes of frozen foods, albeit relatively slow, are very dependent on the storage temperature. For example, $50 \%$ of degradation of vitamin $\mathrm{C}$ in frozen green vegetables occurs in 153 days at $-20^{\circ} \mathrm{C}$ for spinach only in 8 days at $-5^{\circ} \mathrm{C}$, while the respective values for green beans are 311 and 21 days (Giannakourou \& Taoukis, 2003). It becomes evident that temperature monitoring and control within the cold chain is a prerequisite for effective quality management and optimization. In current practice, this is usually handled by reporting on the packages of frozen food arbitrary disclaimers, stating that if the food is stored always at $-18^{\circ} \mathrm{C}$, then the expiry date is valid (and which in practice very rarely occurs), but at any other temperature the food has extremely short shelf life (for example one week at $5^{\circ} \mathrm{C}$ ).

The current philosophy for food quality optimization is to introduce temperature monitoring in an integrated, structured quality assurance system, based mostly on prevention, through the entire lifecycle of the product (Taoukis, Giannakourou, \& Tsironi, 2011). Ideally, what would be needed is a cost effective way to either maintain temperature or to individually monitor the temperature conditions of food products throughout distribution in order to indicate their real quality. This could lead to an effective quality control of the cold chain, optimized stock rotation and waste reduction, as well as enable the estimation of the remaining shelf life at different stages of the cold chain. This calls for con- trol over pallets, control over the cases of product and, finally, over the individual packages at every step in distribution (Symons, 1994).

Application of an optimized quality and safety assurance system for the chilled and frozen distribution of products requires continuous monitoring and control of storage conditions, from production to consumption. Smart packaging systems can provide meaningful information on food quality, either indirectly (e.g. time temperature integrators) or directly (e.g. freshness indicators) (Smolander, 2008). Time-Temperature Integrators (TTI) are inexpensive, active "smart labels" that can show an easily measurable, timetemperature dependent change that reflects the temperature history of a food product to which it is attached (Taoukis \& Labuza, 2003). Their change is based on a physical, enzymatic, chemical or microbiological reaction and is expressed by an irreversible colour change or a colour movement along a scale. The extent to which this change occurs is related to the duration and amount of temperature increase. The visible reaction of the TTI can thus indicate the timetemperature history of the product, changing faster at higher temperature increase. Commercially available TTI are based on various reaction mechanisms (polymerisation, photochromic reactions, diffusion or enzyme reactions) (Taoukis, Doona, Kustin, Feeherry, et al., 2010). They are usually applied in the form of labels on the packaging and thereby act as an indicator. The prerequisite for application of TTI is systematic kinetic modelling of the temperature dependence of shelf life of the target food products. Most Small and Medium-sized Enterprises do not have sufficient data which would enable them to determine the shelf life of their food products for known time-temperature conditions in the real cold chain. Additionally, similar kinetic study is needed for the TTI response. Based on reliable models of shelf life and the kinetics both of the product and the TTI response, the effect of temperature can be monitored, and quantitatively translated to food quality, from production to the point of consumption (Taoukis \& Labuza, 1989a, 1989b; Taoukis, 2001). Most of the studies have been conducted on chilled food, mainly meat and fish products under isothermal and dynamic temperature conditions simulating real 
cold chain scenarios (Mai et al., 2011; Smolander, Alakomi, Ritvanen, Vainionpaa, \& Ahvenainen, 2004; Tsironi, Gogou, Velliou, \& Taoukis, 2008, 2011).

In the IQ-Freshlabel European project (http: //www.iq-freshlabel.eu/) enzymatic and photochromic TTI were developed and tested for frozen products. Methodology was developed for selection of the optimum TTI design of specific frozen fish products and their application was validated in cold chain simulating trials and in pilot studies (Giannoglou, Touli, Platakou, Tsironi, \& Taoukis, 2014). This project further to the technical objectives, aimed to educate the stakeholders (SMEs) regarding the properties of the developed TTIs and their utilization within food packaging, transport, storage and sale. The training activities were addressed at first to SME Associations (SME-AGs) that afterwards conducted training to their members. The workshops involved two phases: shelf life modelling of frozen seafood and TTI theory and application. Training material was developed, including an extended training manual for frozen seafood shelf life testing and application of TTI, PowerPoint ${ }^{\circledR}$ presentations and printed tutorials. The developed training materials, adapted to the meat and fish producers' needs in terms of content and language were distributed to the training attendees and published on the IQ-Freshlabel website (http://iq-freshlabel.eu/402.0.html). Practical demonstrations of the activation of the TTI were carried out during the trainings in order to provide the participants a visual and clearer idea of the TTI operation. The Workshop "Smart packaging: Cold chain management for frozen food quality" was co-organized by the National Hellenic Association of Frozen Foods (PASEKT) and National Technical University of Athens on 26/9/2012. Forty-three SME members were trained on TTI application to frozen food products; the training was carried out using the Greek language. The study involved two phases: methodology for shelf life modelling of frozen seafood and TTI theory and application. The outcome was an increase in the technological level of both the SME-AGs and the SMEs in the addressed sectors.

The objective of the present article is to practically describe a methodology for frozen food shelf life testing and modelling, and the selection of appropriate TTI for specific foods. This document aims to enable SMEs staff to acquire the necessary knowledge regarding the TTI technology and their application in the food chain.

\section{Materials and Methods}

\subsection{Frozen food shelf life testing}

A first estimation of the shelf life of a specific food can be made based on literature review and past experience. Shelf life testing experiments are designed to determine the shelf life of a product under given conditions and validate previous shelf life estimations. The target food products are produced and packed under the desired conditions. A sufficient amount of packages are stored at minimum three isothermal conditions in freezers with temperature control, with the higher temperature reaching abuse conditions that have been reported in the frozen food chain (e.g. $-5,-8$ and $-12^{\circ} \mathrm{C}$ ) (Giannoglou et al., 2014). Temperature in these controlled freezers should be constantly monitored with appropriate data-loggers. This accelerated shelf life testing will enable the determination of the relatively long shelf lives of frozen foods in shorter periods and will evaluate the effect of temperature abuse on the shelf life stability of the product. In addition, kinetic studies at several temperatures are necessary to predict the effect of temperature fluctuations which may occur in distribution and storage on the shelf life of frozen foods. Control samples are also kept at recommended frozen conditions (e.g. $-18^{\circ} \mathrm{C}$ ) to validate the predictions of the accelerated shelf life experiments. The number of samples and controls required should be based on a detailed experimental design. In general, at least 10 packages per storage condition are required. If large quantities of the food packages are available, extra samples should be placed into each storage condition (Fu \& Labuza, 1997). Samples are taken at appropriate time intervals to allow for efficient kinetic analysis of quality deterioration.

Quality assessment of the target frozen food is based on several physicochemical parameters 
(i.e. colour, texture, $\mathrm{pH}$, total volatile nitrogenTVBN, lipid oxidation-TBARS). The selected quality indices can be based on literature review and previous experiments conducted on similar products. The sensory attributes of frozen and cooked samples are evaluated by a sensory panel of 6-8. Thawed samples are cooked individually wrapped in aluminium foil, at $180^{\circ} \mathrm{C}$ for sufficient time (e.g. $20 \mathrm{~min}$ ). Frozen products should be first examined in the frozen state, especially for products packed in transparent package. Panellists develop a list of profiling attributes concerning appearance and odour of thawed samples and appearance, odour, texture and flavour of cooked samples. The sensory parameters are evaluated using descriptive terms and recorded in appropriate forms, reflecting the organoleptic evolution of quality deterioration. Rating is assigned separately for each parameter on a 1 to 9 scale (9 being the highest quality score and 1 the lowest). Additionally, panellists are asked to evaluate the overall impression and acceptability, using a 1 to 9 scale, indicating the general impression of the product (frozen, thawed and cooked). Samples were considered acceptable if their score for overall impression were above 5 (medium quality), coinciding with slight off odour and off taste development. If a 1-3 scale is used, the limit of acceptability is set between 2 and 3 (FAO, 1995). The definition of shelf life and the criteria for the determination of the end of shelf life are dependent on specific commodities and on the definition's intended use (i.e. for regulatory vs. marketing purposes) (Barbosa, Bremner, \& Vaz-Pires, 2002).

The criterion for the limits of acceptability for shelf life determination, based on the quality determining parameters, may be variable. Frozen foods degrade mainly by slow chemical reactions such as loss of nutritional value (e.g. vitamin $\mathrm{C}$ content for some frozen fruits and vegetables) or other chemical changes (e.g. development of lipid oxidation resulting in the typical rancid taste). Values of the different measured indices are plotted vs time for all temperatures studied and mathematical equations that most adequately fit the data are selected (FAO, 1995; Giannakourou \& Taoukis, 2003; Dermesonluoglu, Katsaros, Tsevdou, Giannakourou, \& Taoukis, 2015; Giannoglou et al.,
2014). Chemical or instrumental measurement that closely correlates to sensory changes can be the criterion for shelf life evaluation.

The Arrhenius equation (Equation 1) is often used to describe the temperature dependence of deterioration rate

$$
k(T)_{t}=k_{\text {ref }} \exp \left(\frac{-E_{A}}{R}\left(\frac{1}{T}-\frac{1}{T_{\text {ref }}}\right)\right)
$$

where $\mathrm{k}_{\text {ref }}$ is a pre-exponential factor which represents the rate constant of the degradation of the respective quality index at a reference temperature, $\mathrm{T}_{\text {ref }}$ (e.g. $-5^{\circ} \mathrm{C}$ for frozen foods), $\mathrm{T}$ is the temperature in $\mathrm{K}, \mathrm{E}_{a}$ is the activation energy of the studied action indicating its temperature dependence and $\mathrm{R}$ is the universal gas constant (Taoukis, Labuza, \& Saguy, 1997). Thus, by studying a deterioration process and measuring the rate of loss at two or three temperatures (higher than storage temperature), one could then extrapolate on an Arrhenius plot to predict the deterioration rate at the desired storage temperature. This is the basis for accelerated shelf life testing (ASLT). However, it should be noted that for frozen foods extrapolation from temperatures above $0^{\circ} \mathrm{C}$ are meaningless for shelf life prediction ( $\mathrm{Fu} \&$ Labuza, 1997).

\subsection{TTI response study}

A sufficient amount of TTI labels were obtained for use at three storage temperatures. The labels were activated according to the guidelines given by the TTI provider and were adhered to a glass plate. Glass has high thermal capacity and thus the temperature of the labels during the short time of measurement was not affected. Multiple TTI samples were isothermally stored in controlled freezers, e.g. at $-5,-8$ and $-12^{\circ} \mathrm{C}$. Satisfactory temperature stability was achieved with commercial freezers, by installation of high precision temperature controllers. The temperature profile of each freezer was recorded during the experiments using low cost, programmable, downloadable data loggers. Testing of the TTIs was based on measurements, at appropriate time intervals of the colour change of multiple TTI samples (3-5 samples per temperature, per enzyme concentration for the enzymatic and per 
charging time for the photochromic TTI labels). This could be carried out using a colorimeter, if available. Values of the different colour parameters (i.e. L, a, b) were plotted vs time for all temperatures studied and mathematical equations that most effectively describe their changes were selected. Alternatively, visual evaluation of the TTI response changes could be conducted. To assist this visual reading colour scales could be employed.

For this study multi point colour scales, one for each type of the studied TTI labels, were constructed and used for TTI colour evaluation by the panel. For the construction of the colour scales, TTI labels were activated and left at $\mathrm{T}=25^{\circ} \mathrm{C}$. When a colour change was visually observed, the colour of the TTI was instrumentally measured and then the label was numbered and placed on a glass surface which was then stored at $-30^{\circ} \mathrm{C}$. Thus, each label of the constructed colour scales corresponded to a specific measurement of colour (i.e. L, a, b). This procedure was repeated for the whole range of colour change for each TTI type. To confirm that visual scoring gives results similar to the respective ones obtained by the instrumentally measured colour of the labels, panellists were asked to compare the labels' colour with the numbered colour scale. The L, a, b values estimated by the colorimeter were then compared to the $\mathrm{L}, \mathrm{a}, \mathrm{b}$ values of the label indicated by the panellists. The colour scales should be stored at $-30^{\circ} \mathrm{C}$ and they were frequently checked to ensure colour stability (in case of decolourisation of the TTIs the colour scale must be replaced). The response time (i.e. time from activation to endpoint, as defined by the TTI provider) at each studied temperature was determined.

Two different TTI smart labels were studied within IQ-Freshlabel project, the one was enzymatic and the second a solid state photochromic TTI. The enzymatic indicators' function was based on a colour change caused by a $\mathrm{pH}$ decrease that is due to the controlled enzymatic hydrolysis of a lipid substrate. The colour change of the M-type enzymatic TTI (M Check Point ${ }^{\circledR}$, VITSAB, Malmo, Sweden) was due to a controlled enzymatic hydrolysis by a microbial lipase (Rhizopus Oryzae lipase) of a lipid substrate (methylmyristate). This TTI changes from an initial green colour, becomes progressively yellow/orange and reaches a final red colour. Mtype enzymatic TTI with different enzyme concentrations ( 4 to $44 \mathrm{U}$ ) were used and kinetically modelled (Giannoglou et al., 2014).

The OnVuTM TTI (B1 OnVuTM, Bizerba, Germany) was based on the inherent reproducibility of reactions in crystal phase (Patent EP 1049930 B1). Photosensitive compounds, such as spiropyrans, are excited and coloured by exposure to low wavelength light. This coloured state (dark blue) reverts to the initial colourless with a temperature dependent reaction rate. By controlling the type of the photochromic compound and the length of UV light exposure during activation the length and the temperature sensitivity of the TTI can be set (Tsironi et al., 2011). The B1 TTI was charged (Bizerba Desktop Charger, Bizerba GmbH \& Co. KG, Balingen, Germany) for 0.1 to $1 \mathrm{~s}$ (charging time of $1 \mathrm{~s}$ corresponds to energy of $50 \mathrm{~mJ} / \mathrm{cm}^{2}$ ) and subsequently laminated with an optical filter (TTR 70QC) to protect TTI from light exposure and recharging (Giannoglou et al., 2014; Tsironi et al., 2011).

\section{Results and Discussion}

\subsection{Frozen food shelf life testing}

To more effectively describe the methodology for frozen food shelf life testing, frozen whole unpeeled shrimp was presented as a test case. The experimental procedure was based on a previous shelf life study reported by Tsironi, Dermesonlouoglou, Giannakourou, and Taoukis (2009). The aim of this work was to evaluate the shelf life of whole frozen shrimp provided by another food producer and validate the previously reported kinetic models. The experimental design and the results of the current experiment are presented below. Whole unpeeled frozen shrimp (Penaeus notialis, size: 5, origin: Atlantic ocean, Easter central, FAO 34) packed in their usual commercial packages (cardboard lined with HDPE film, weight: 500 g) were obtained directly from the packer. 80 packages in total were distributed and stored at controlled temperature cabinets (Sanyo MIR 553, Sanyo Electric Co, Ora-Gun,Gunma, 
Japan) at constant temperatures $(-15,-12,-8$ and $\left.-5^{\circ} \mathrm{C}\right)$. Electronic, programmable, miniature data loggers $\left(\right.$ COX TRACER ${ }^{\circledR}$, Belmont, NC) constantly monitored the temperature in the incubators. Measurements of selected quality indices were conducted during a 14-month period, and data were analysed and modelled. Before analysis, samples were thawed at room temperature. Thawing was accelerated by immersion of the material in water. This is acceptable if product is protected from the contact with water by suitable wrappings, or if contact with water does not materially affect the sensory properties of the product (CAC/GL 3 , 1999). All determinations were made in duplicate samples.

2-Thiobarbituric acid reactive substances (TBARS), that evaluate lipid oxidation, has been considered as good quality index for frozen shrimp (Boonsumrej, Chaiwanichsiri, Tantratian, Suzuki, \& Takai, 2007; Bono, Badalucco, Cusumano, \& Palmegiano, 2012). TBARS assay was performed according to the method developed by Lovaas (1992). TBARs were determined for thawed shrimp flesh. According to the methodology described above, from each test storage conditions (i.e. $-5,-8,-12$ and $-15^{\circ} \mathrm{C}$ ) TBARs and sensory scoring were plotted vs time (Figure $1 \mathrm{a}$ and $1 \mathrm{~b}$, respectively). Both changes were described adequately by linear equations $\left(\mathrm{R}^{2}>0.94\right.$ in all cases). Sensory scoring (overall impression) decreased with time following zero order kinetics $\left(\mathrm{R}^{2}>0.97\right.$ in all cases $)$. The sensory characteristics at the point of organoleptic rejection were sour, fish off flavours for the cooked samples together with dry texture and discolouration of shrimp shell in the thawed product. Severe blackening in the head and gill regions was observed after one month of storage at $-5^{\circ} \mathrm{C}$. All samples stored at lower that $-8^{\circ} \mathrm{C}$ had acceptable appearance before thawing during storage. The results obtained at higher storage temperatures (i.e. -5 and $-8^{\circ} \mathrm{C}$ ) indicated slightly faster quality deterioration for frozen shrimp than the respective data reported by Tsironi et al. (2009), which was attributed to lower amounts of ice glazing, species diversity, sample orientation and fat content. Gonçalves and Junior (2009) reported that a reasonable range of water uptake during glazing could be between $15 \%$ and $20 \%$ to guarantee the final quality of frozen shrimp. Temperature dependence of the rates of TBARs and sensory changes were adequately described by Arrhenius kinetics (Equation 1) in the temperature range studied (i.e. -5 to $-15^{\circ} \mathrm{C}$ ). The activation energy values, $\mathrm{E}_{a}$, were determined at 132.5 and 111.6 $\mathrm{kJ} / \mathrm{mol}$, respectively $\left(\mathrm{T}_{r e f}=-15^{\circ} \mathrm{C}\right)$.

To define a threshold TBARs value for frozen shrimp shelf life determination, Figures $1 \mathrm{a}$ and $1 \mathrm{~b}$ were merged. A sensory score of 5 was taken as the average score for minimum acceptability. As shown in Figure 1c, the limit of sensory shelf life coincided with a TBARs value of 3 $\mathrm{mg} \mathrm{MDA} / \mathrm{kg}$. The shelf life of frozen shrimp as determined based on sensory evaluation and TBARs changed as shown on Table 1. Shelf life plots are practical and easier to understand as the shelf life of the food can be read directly at any storage temperature. The shelf life of frozen shrimp at all storage temperatures is illustrated in Figure 2.

\section{$3.2 \quad$ TTI response study}

The response time of the two types of TTI tested for use by SMEs for a target product as the studied frozen shrimp was determined using colour scales consisting of TTIs at different levels of colour change. These scales are shown in Fig. 3a and $3 \mathrm{~b}$. End point colour was noted by a single value in the scale of each TTI. For M-type enzymatic TTI label end point value was 12 and for B1 photochromic TTI label end point value was 18. It was confirmed that visual scoring with the use of such scales give results that do not differ statistically from instrumental colour measurement.

Based on the above described methodology, the total response times (time from activation to endpoint) of the studied TTI labels for the different enzyme concentrations or charging times and at different storage temperatures were illustrated in Figures 4a and 4b respectively. It is evident that the lower the enzyme concentration or the higher the charging time of the TTI, the longer the shelf life at a given storage temperature. 
154| Tsironi et al.

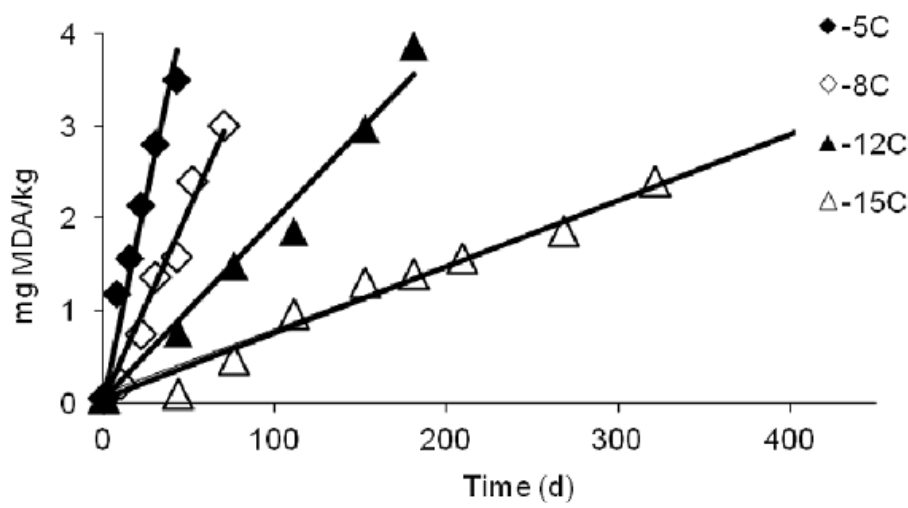

a)

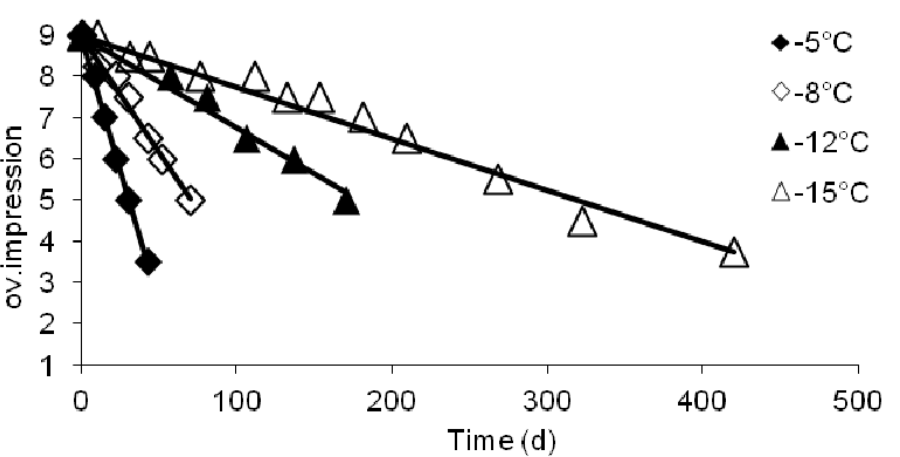

b)

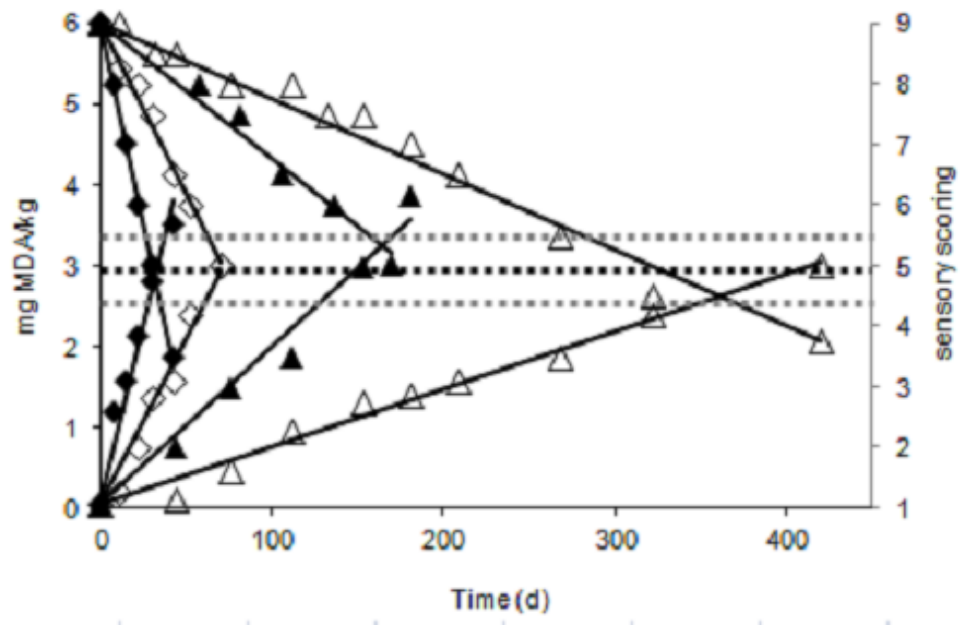

Figure 1: (a) Evolution of lipid oxidation (TBARs), and (b) sensory scoring (overall impression) of frozen shrimp during isothermal storage at $-5,-8,-12$ and $-15^{\circ} \mathrm{C}$. (c) Correlation of TBARs value with sensory scoring (overall impression) for the determination of TBARs limit for shelf life estimation (horizontal lines: average TBARs limit \pm standard deviation) 
SMEs training for cold chain management $\mid 155$

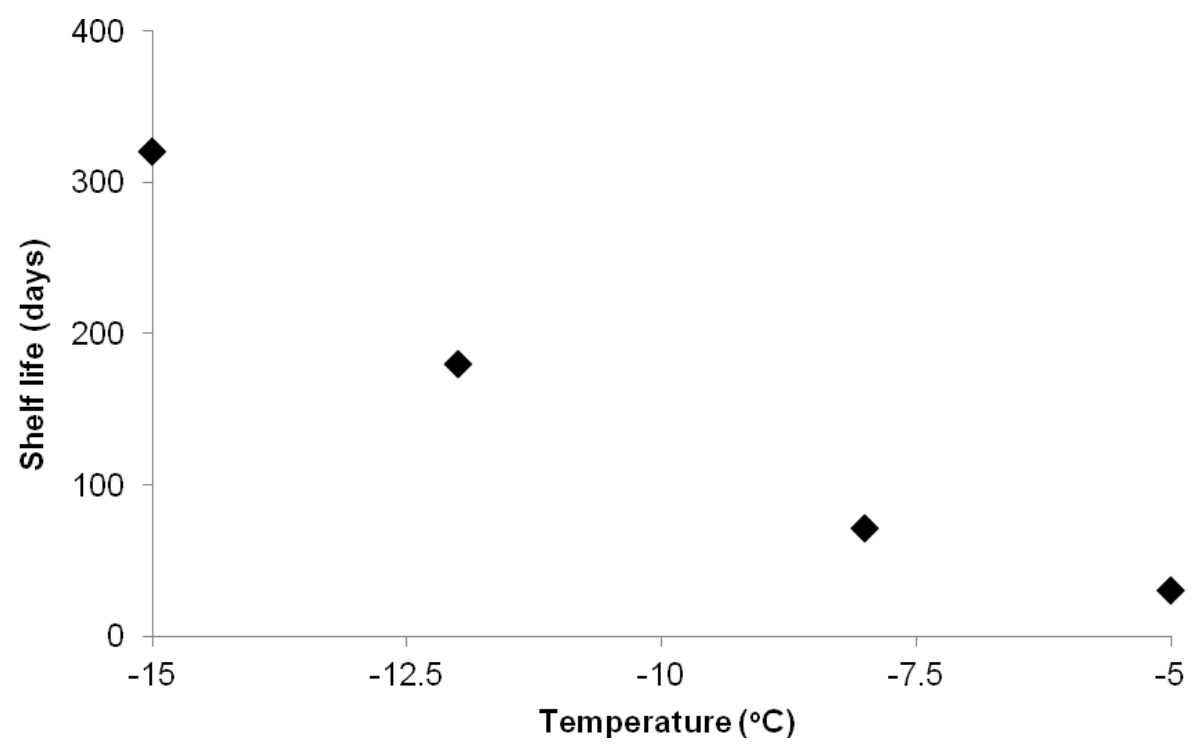

Figure 2: Shelf life (days) of frozen shrimp stored isothermally in the range -5 to $-15^{\circ} \mathrm{C}$

Table 1: Shelf life of frozen shrimp stored at $-5,-8,-12,-15$ and $-18^{\circ} \mathrm{C}$

\begin{tabular}{ccc}
\hline \multicolumn{3}{c}{ Shelf life (d) } \\
\hline $\begin{array}{c}\text { Storage } \\
\text { temperature } \\
\left({ }^{\circ} \mathbf{C}\right)\end{array}$ & $\begin{array}{c}\text { Sensory scoring } \\
(\text { limit=5 score) }\end{array}$ & $\begin{array}{c}\text { TBARs } \\
(\text { limit=3 mg } \\
\text { MDA/kg) }\end{array}$ \\
\hline-5 & 34 & 34 \\
-8 & 67 & 68 \\
-12 & 173 & 178 \\
-15 & 359 & 374 \\
$-18^{*}$ & 758 & 799 \\
\hline
\end{tabular}

*Calculated

\subsection{Selection of appropriate TTI for monitoring the quality of frozen shrimp}

To select the appropriate enzyme concentration or charging time, based on the shelf life studies on the target frozen food product and the response profiles of the TTI, the shelf life curves of the TTI and the food were combined to obtain an adequate match between the product shelf life and the response time of the TTI label in the frozen range (e.g. $-15^{\circ} \mathrm{C}$ ), as shown in Figures 4a and $4 \mathrm{~b}$ for frozen shrimp and the selected M$15 \mathrm{U}$ enzymatic and B1-0.15s photochromic label, respectively. Practically, this required the TTI response kinetics to be similar to the kinetics of quality loss of the food product, which meant similar $\mathrm{E}_{A}$ values. This close match is not always observed as shown in Figure 5, where the M-type enzymatic TTI were investigated to monitor the shelf life of frozen gilthead seabream (Sparus aurata) fillets. In this case, a suitable TTI could be selected if it showed satisfactory correlation with the target food product in the temperature range of -5 to $-12^{\circ} \mathrm{C}$ and at lower (recommended) stor-

\begin{tabular}{l|l|l|l} 
IJFS & October 2015 | Volume 4 & pages 148-162
\end{tabular} 
a)
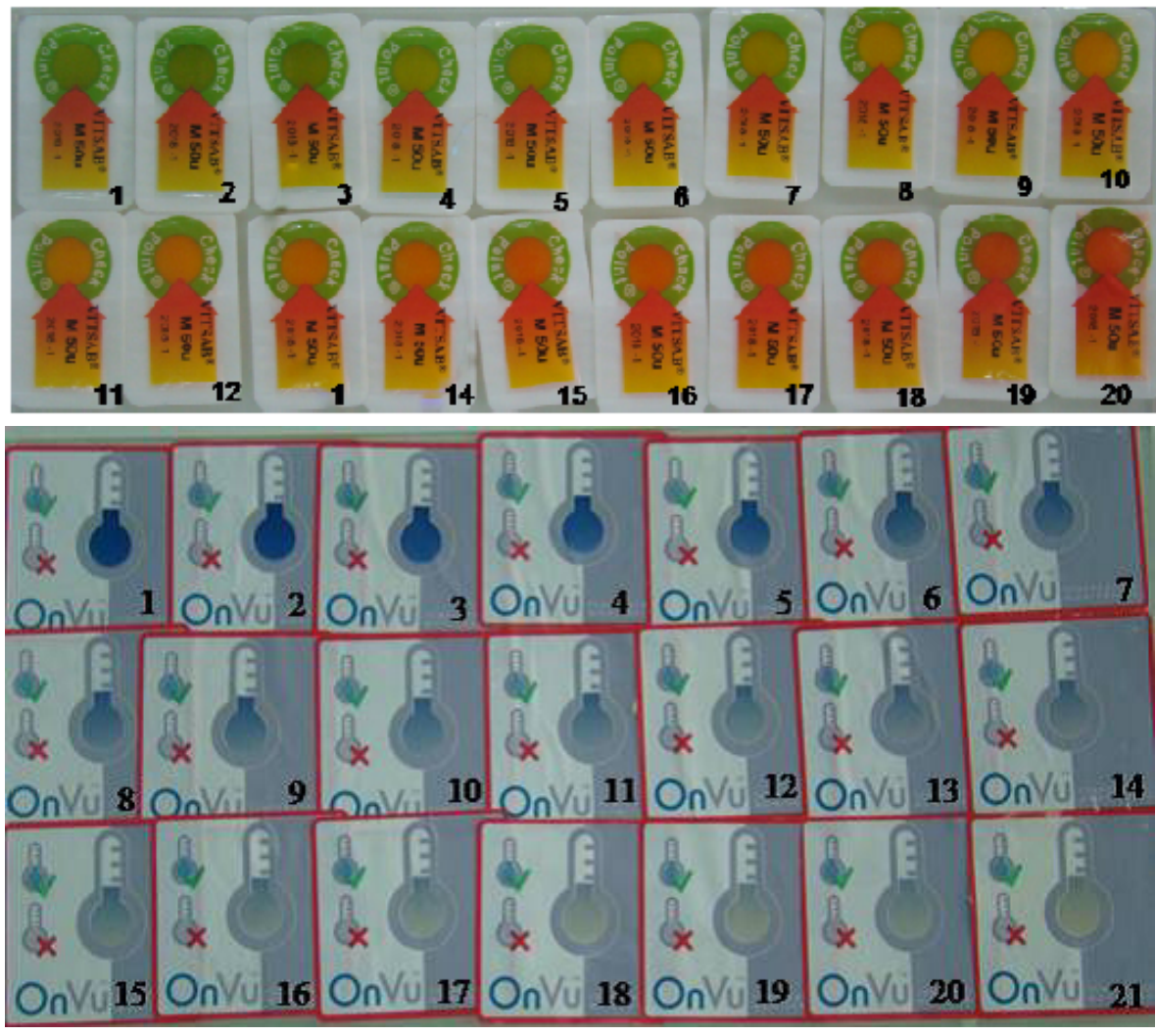

Figure 3: (a) M-type enzymatic TTI label colour scale, (b) B1 photochromic TTI label colour scale)

age temperatures it showed higher response times than the respective shelf life of the food. Based on this selection (i.e. M-10U enzymatic TTI for frozen gilthead seabream fillets), if the products were stored at very low temperatures (i.e. below $-12^{\circ} \mathrm{C}$ ) the end of shelf life would be determined and limited by the expiration date on the food package. On the other hand, if abuse temperatures prevailed, then the TTI would conservatively signal poor quality products just before the end of shelf life. In general, a TTI with an $\mathrm{E}_{A}$ within $\pm 20 \mathrm{~kJ} / \mathrm{mol}$ of the activation energy of the selected quality index of the target food product could be used to satisfactorily monitor its shelf life.

\subsection{Validation of the applicability of the selected TTI for monitoring the quality of frozen shrimp at dynamic conditions}

To validate the applicability of the selected TTI for monitoring the quality of frozen shrimp in the real chill chain, a laboratory scale experiment simulating abusive cold chain conditions of storage was designed. The selected TTI (M$15 \mathrm{U}$ enzymatic and B1-0.15s photochromic label) were attached on the frozen shrimp packages, which were stored at controlled temperature cabinets (Sanyo MIR 553, Sanyo Electric Co, Ora-Gun,Gunma, Japan) at variable temperature conditions. The time temperature scenario (Var) included repeated cycles of three isothermal steps of $12 \mathrm{~h}$ each (i.e. $12 \mathrm{~h}$ at $-5^{\circ} \mathrm{C}, 12$ 
SMEs training for cold chain management $\mid 157$

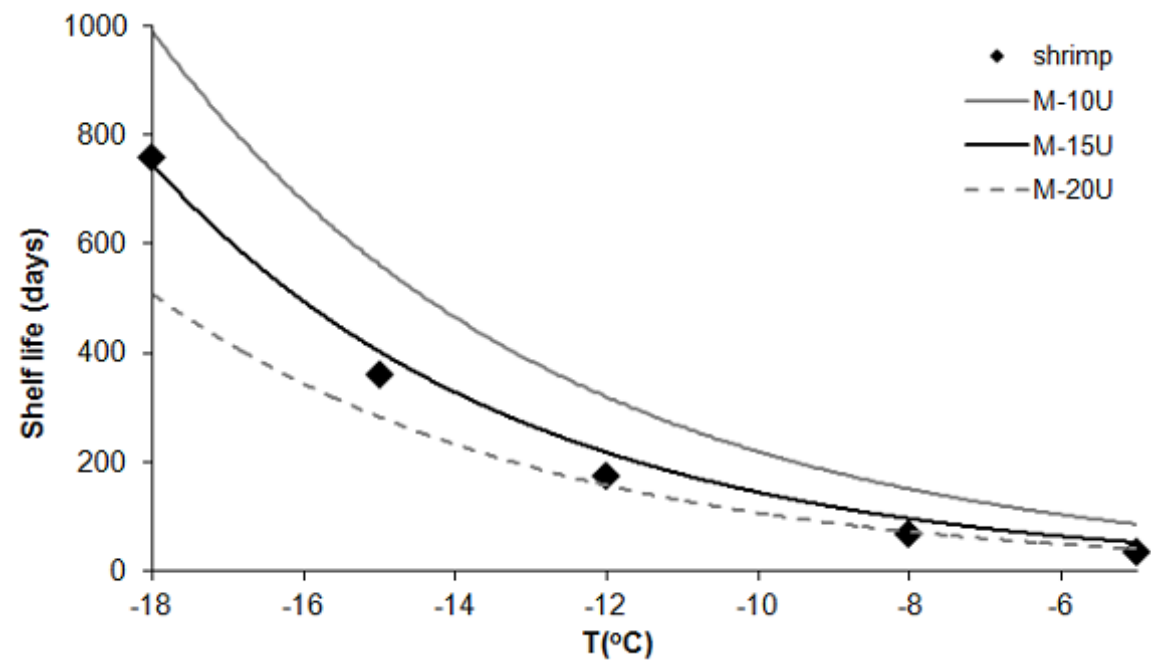

a)

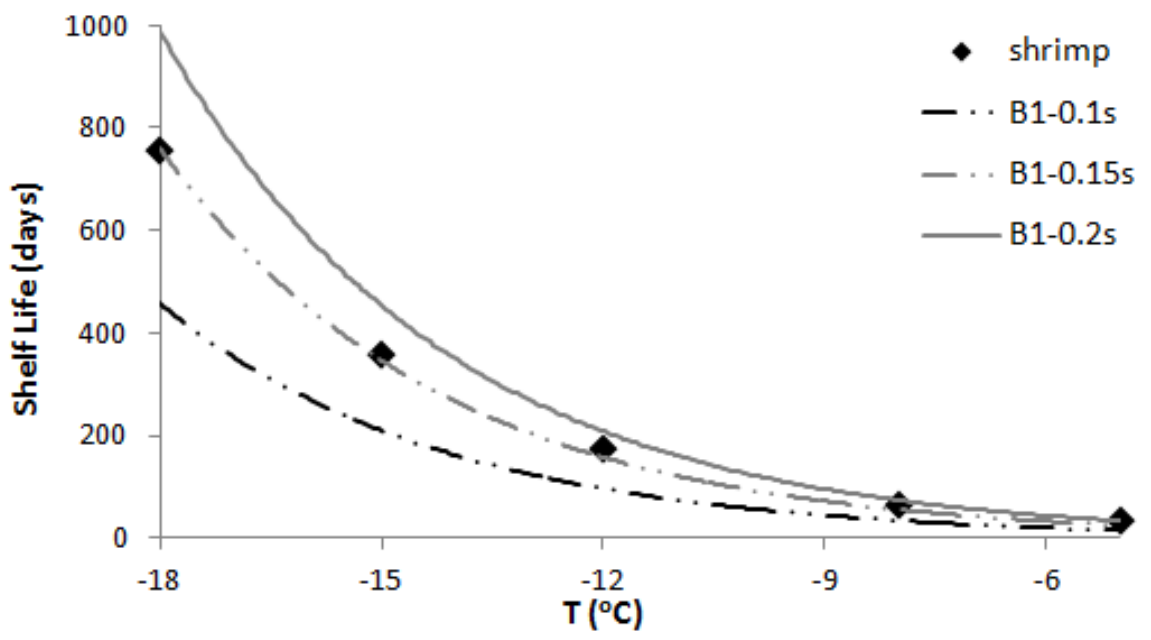

b)

Figure 4: Shelf life (days) of frozen shrimp at different storage temperatures $\left(\mathrm{E}_{A, \text { shrimp }}=136.2 \mathrm{~kJ} / \mathrm{mol}\right)$ together with the tested TTI response curves: (a) M-type enzymatic TTI $\left(\mathrm{E}_{A, M-t y p e}=111.6 \mathrm{~kJ} / \mathrm{mol}\right)$ and (b) B1 photochromic TTI $\left(\mathrm{E}_{A, B 1}=123.2 \mathrm{~kJ} / \mathrm{mol}\right)$ 
$158 \mid$ Tsironi et al.

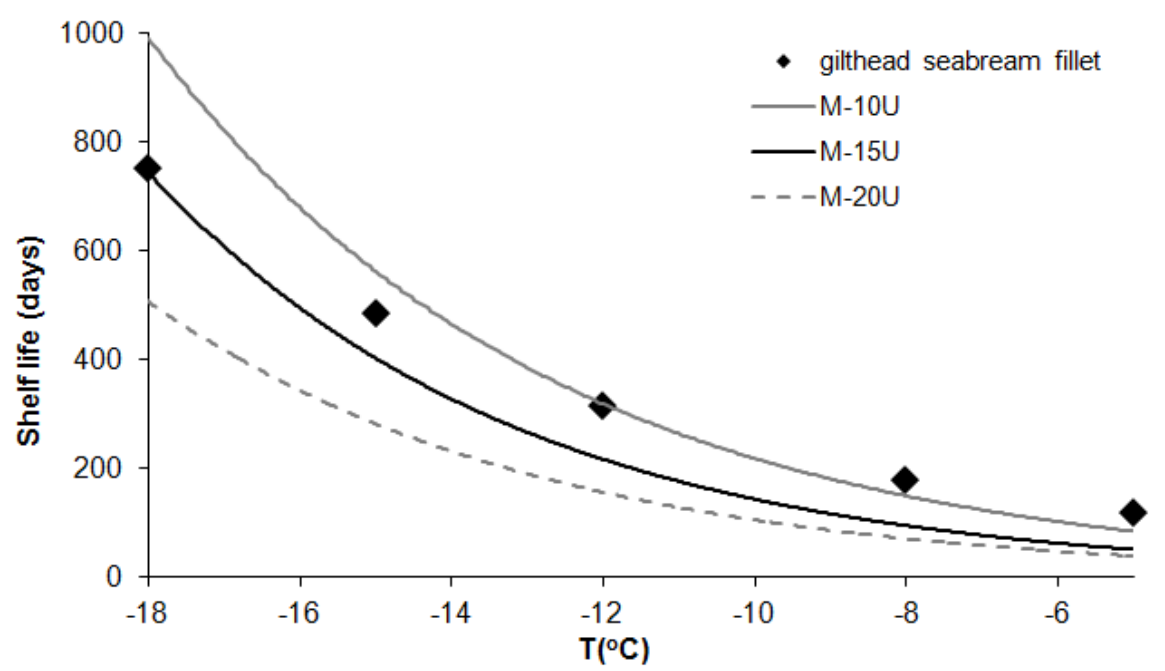

Figure 5: Shelf life (days) of frozen gilthead seabream fillets $\left(\mathrm{E}_{A \text {, seabream }}=80.3 \mathrm{~kJ} / \mathrm{mol}\right)$ together with the tested M-type enzymatic TTI response curves $\left(\mathrm{E}_{A, M-\text { type }}=111.6 \mathrm{~kJ} / \mathrm{mol}\right)$

$\mathrm{h}$ at $-8^{\circ} \mathrm{C}$ and $12 \mathrm{~h}$ at $\left.-10^{\circ} \mathrm{C}\right)$. Temperature in the incubators was constantly monitored with electronic, programmable miniature data loggers (COX TRACER ${ }^{\circledR}$, Belmont, NC). Samples were taken in appropriate time intervals. The response of the attached TTIs was estimated in parallel with the quality deterioration of shrimp, in order to validate their effectiveness for monitoring quality of frozen shrimp at dynamic conditions. The quality level and remaining shelf life (at $\mathrm{T}_{r e f}=-15^{\circ} \mathrm{C}$ ) at predetermined times was estimated based on the response of the TTI (indicating the time-temperature history of the food product) and the values were compared to actual measured values of the quality indices (TBARs and sensory evaluation) as shown in Fig. 6 .

The comparison between the experimental (actual) and predicted (calculated by the TTI measurement) was based on the accuracy factor (Equation 2)

accuracy factor $=10 \frac{\sum \mid \log \left(\mathrm{y}_{\text {predicted }} / \mathrm{y}_{\text {experimental }}\right)}{n}$

where $\mathrm{n}$ is the number of observations. Perfect agreement between predicted and observed values was represented by an accuracy factor of 1 (Ross, Dalgaard, \& Tienungoon, 2000).

The accuracy factors (1.033 and 1.012 for M-
15U enzymatic and B1-0.15s photochromic TTI, respectively), indicated that there was a good agreement between predicted and observed $\mathrm{SL}_{R}$ values. The validation experiment supported the applicability of the selected TTI labels to monitor the quality of frozen shrimp under nonisothermal conditions and hence in the dynamic temperature conditions of the real chill chain.

The frozen food industry can significantly benefit from the TTI technology. The quality changes caused by exposure to higher than recommended sub-zero temperatures result in considerable decrease of shelf life of the food products. The expiration date ensures product quality only for storage under recommended conditions (below $\left.18^{\circ} \mathrm{C}\right)$. However, during the post-production life cycle of the frozen food products deviations affecting the quality arise. Temperature monitoring is the solution for improving the cold chain of the food products and decrease waste prior to the expiration date. The selection of appropriate TTI labels for a particular product could lead to realistic control of the cold chain, while reliable estimation of the quality status and the remaining shelf life could be performed, allowing better management and optimization from production to the point of consumption. Attached to 
SMEs training for cold chain management $\mid 159$

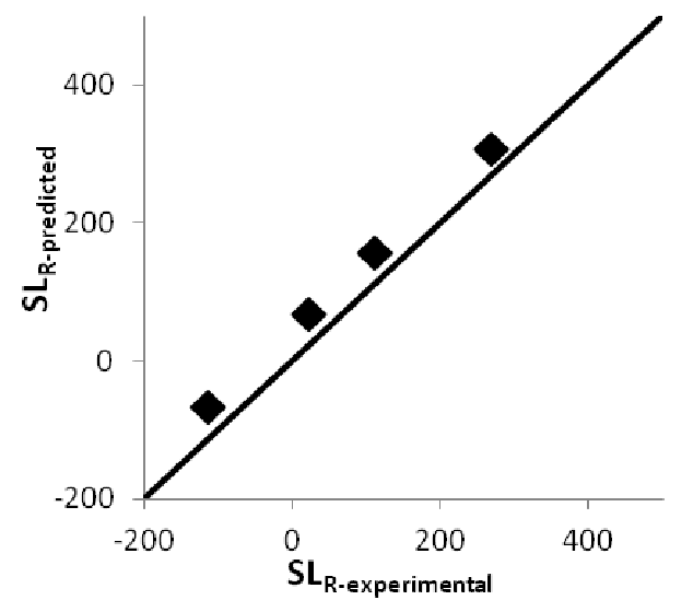

a)

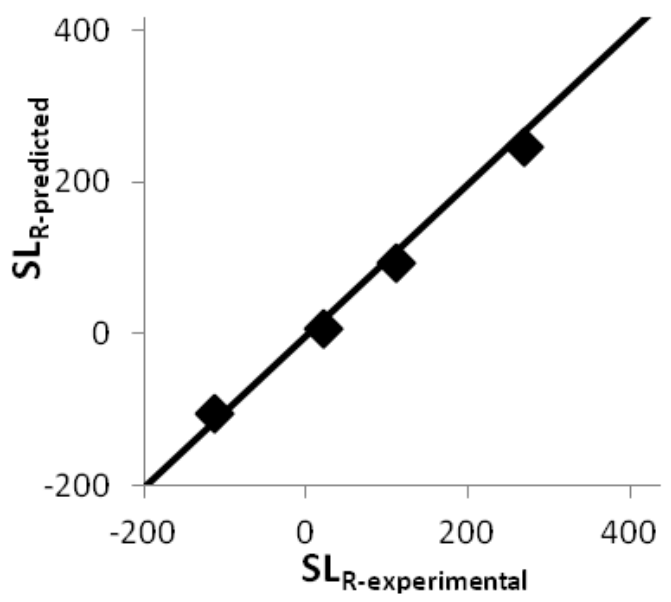

Figure 6: Correlation of the actual remaining shelf life in days $\left(\mathrm{SL}_{R}\right.$-experimental $)$ of frozen shrimp at $\mathrm{T}_{r e f}=-15^{\circ} \mathrm{C}$ estimated by experimental determination of quality deterioration (sensory evaluation) with the $\mathrm{SL}_{R-\text { predicted }}$ calculated by the TTI response (a) M-15U enzymatic TTI (accuracy factor=1.033) and (b) B1-0.15s photochromic TTI (accuracy factor=1.012) 
individual cases or pallets, TTI can provide information regarding the preceding temperature conditions at specific control points. This may serve as a proof of compliance to contractual requirements by the producer and distributor. TTI can also guarantee the proper handling of food products during transportation and distribution, thus eliminating the possibility of unsubstantiated rejection claims by retailers. At the same time, TTI labels attached to the surface of a food package intend to integrate the cumulative timetemperature history of the specific food product throughout the whole cold chain, from production to the point of consumption, and hence provide information on the food quality.

\section{Conclusions}

Overall, the methodology for shelf life testing of frozen foods and the response of TTI smart labels was demonstrated. Based on the storage tests results, appropriate TTI were selected for monitoring the quality of frozen shrimp, as a case study. Furthermore, the value of systematic modelling of the food quality kinetics as well as the response of the TTI in building an effective chill chain management system was also demonstrated. The TTI response study allowed a reliable optimization and selection of TTI to be correlated to the target food product for which accurate information on temperature dependence is available. To cumulatively reflect the quality changes of the frozen food product, the required TTI should have a total response time of many months at $18^{\circ} \mathrm{C}$ and several weeks at $-5^{\circ} \mathrm{C}$ to $-8^{\circ} \mathrm{C}$. If the TTI response is not long enough, properly stored and of good quality, products will be falsely indicated as having problem. Thus, the smart food labels are one way of effective communication of quality status and risk associated with food product to food retailers and consumers. Moreover the application of TTI that monitors the quality of food contributes to the traceability approaches and fills the gap of missing information between the different stages of the supply chain.

The IQ-Freshlabel training courses were developed to provide SMEs with skills in the frozen food shelf life evaluation and cold chain management. The training encouraged participants to monitor cold chain more effectively by implementing experimental shelf life testing and by selecting appropriate TTI smart labels for specific frozen food products. The training approach was designed to offer the participants insights into the theoretical background of frozen food quality, current legislation and cold chain management. In total, more than 276 companies and consumers representing the frozen food industry, the packaging industry, the meat industry, the seafood industry and food business operators in Greece, Finland, Romania, Poland, France and Norway were successfully trained. Through the publication of the training material translated in various languages, further impact on the European chilled and frozen food products chain was reached.

\section{Acknowledgements}

This study was supported by the European Commission FP7 Collective Research Project IQFreshlabel "Developing novel intelligent labels for chilled and frozen food products and promoting the influence of smart labels application on waste reduction, food quality and safety in the European supply chains" FP7-SME-2008-2243423 (http://www.iq-freshlabel.eu).

\section{References}

Barbosa, A., Bremner, A., \& Vaz-Pires, P. (2002). Safety and quality issues in fish processing. (Chap. The meaning of shelf-life, pp. 173-190). Woodhead Publishing Limited Cambridge, UK.

Bono, G., Badalucco, C. V., Cusumano, S., \& Palmegiano, G. B. (2012). Toward shrimp without chemical additives: a combined freezing-map approach. LWT-Food Science and Technology, 46(1), 274-279. doi:10 . 1016/j.lwt.2011.09.020

Boonsumrej, S., Chaiwanichsiri, S., Tantratian, S., Suzuki, T., \& Takai, R. (2007). Effects of freezing and thawing on the quality changes of tiger shrimp (penaeus monodon) frozen by air-blast and cryogenic freezing. Journal of Food Engineering, 80(1), 292299. doi:10.1016/j.jfoodeng.2006.04.059 
Dermesonluoglu, E., Katsaros, G., Tsevdou, M., Giannakourou, M., \& Taoukis, P. (2015). Kinetic study of quality indices and shelf life modelling of frozen spinach under dynamic conditions of the cold chain. Journal of Food Engineering, 148, 13-23. SI: Cold Chain refrigeration. doi:10.1016/j . jfoodeng.2014.07.007

FAO. (1995). Quality and quality changes in fresh fish. FAO Fisheries Technical Paper348, Food and Agriculture Organization of the United Nations. Rome. Retrieved from http : / / www . fao . org / docrep / v7180e / v7180e00.htm

Fu, B. \& Labuza, T. P. (1997). Shelf-life testing: procedures and prediction methods. In Quality in frozen food (pp. 377-415). Springer.

Gates, K. W., Eudaly, J. G., Parker, A. H., \& Pittman, L. A. (1985). Quality and nutritional changes in frozen breaded shrimp stored in wholesale and retail freezers. Journal of Food Science, 50(4), 853-868. doi:10.1111/j.1365-2621.1985.tb12965.x

Giannakourou, M. C. \& Taoukis, P. S. (2003). Application of a tti-based distribution management system for quality optimization of frozen vegetables at the consumer end. Journal of Food Science, 68(1), 201209. IFT 2001 Annual Meeting, NEW ORLEANS, LOUISIANA, JUN 23-27, 2001. doi:10.1111/j.1365-2621.2003.tb14140.x

Giannoglou, M., Touli, A., Platakou, E., Tsironi, T., \& Taoukis, P. S. (2014). Predictive modeling and selection of tti smart labels for monitoring the quality and shelflife of frozen seafood. Innovative Food Science \&6 Emerging Technologies, 26, 294301. doi:10.1016/j.ifset.2014.10.008

Gonçalves, A. A. \& Junior, C. S. G. G. (2009). The effect of glaze uptake on storage quality of frozen shrimp. Journal of Food Engineering, 90(2), 285-290. doi:10.1016/j. jfoodeng.2008.06.038

Lovaas, E. (1992). A sensitive spectrophotometric method for lipid hydroperoxide determination. Journal of the American Oil Chemists Society, 69(8), 777-783. doi:10. $1007 / \mathrm{BF} 02635914$
Mai, N., Audorff, H., Reichstein, W., Haarer, D., Olafsdottir, G., Bogason, S. G., ... Arason, S. (2011). Performance of a photochromic time-temperature indicator under simulated fresh fish supply chain conditions. International Journal of Food Science and Technology, 46(2), 297-304. doi:10.1111/ j.1365-2621.2010.02475.x

Ross, T., Dalgaard, P., \& Tienungoon, S. (2000). Predictive modelling of the growth and survival of listeria in fishery products. International Journal of Food Microbiology, 62(3, SI), 231-245. doi:10.1016/S0168-1605(00) 00340-8

Smolander, M., Alakomi, H. L., Ritvanen, T., Vainionpaa, J., \& Ahvenainen, R. (2004). Monitoring of the quality of modified atmosphere packaged broiler chicken cuts stored in different temperature conditions. a. time-temperature indicators as qualityindicating tools. Food Control, 15(3), 217 229. doi:10.1016/S0956-7135(03)00061-6

Smolander, M. (2008). Freshness indicators for food packaging. Smart packaging technologies for fast moving consumer goods, 111123.

Symons, H. (1994). Frozen foods. In C. Man \& A. Jones (Eds.), Shelf life evaluation of foods (pp. 296-316). Springer US. doi:10.1007/ 978-1-4615-2095-5_15

Taoukis, P. S., Doona, C. J., Kustin, K., Feeherry, F. E., et al. (2010). Case studies in novel food processing technologies. (Chap. Commercialization of active food packaging (Time-Temperature IntegratorsTTI), pp. 351-366). Woodhead Publishing Ltd.

Taoukis, P. S., Giannakourou, M. C., \& Tsironi, T. N. (2011). Handbook of frozen food processing and packaging. In D.-W. Sun (Ed.), (Chap. Monitoring and control of the cold chain, pp. 273-299). Boca Raton: CRC Press, Taylor \& Francis.

Taoukis, P. S. \& Labuza, T. P. (1989a). Applicability of time-temperature indicators as shelf-life monitors of food-products. Journal of Food Science, 54(4), 783-788. doi:10. 1111/j.1365-2621.1989.tb07882.x

Taoukis, P. S. \& Labuza, T. P. (1989b). Reliability of time-temperature indicators as food 
quality monitors under non-isothermal conditions. Journal of Food Science, 54 (4), 789-792. doi:10.1111/j.1365-2621.1989. tb07883.x

Taoukis, P. S. \& Labuza, T. P. (2003). Novel food packaging techniques. In R. Ahvenainen (Ed.), (Chap. Time-temperature indicators (TTIs), pp. 103-126). Woodhead Publishing Limited UK.

Taoukis, P. S., Labuza, T. P., \& Saguy, I. S. (1997). Handbook of food engineering practice. In R. P. S. K. J. Valentas E. Rotstein (Ed.), (Chap. Kinetics of food deterioration and shelf-life prediction, pp. 361-403). CRC Press Boca Raton, FL.

Taoukis, P. (2001). Food process modelling. In L. M. M. Tijkskens \& B. M. N. M. L. A. T. M. Hertog (Eds.), (Chap. Modelling the use of time-temperature indicators in distribution and stock rotation, pp. 402-432). CRC Press Cambridge, UK.

Tsironi, T., Dermesonlouoglou, E., Giannakourou, M., \& Taoukis, P. (2009). Shelf life modelling of frozen shrimp at variable temperature conditions. LWT-Food Science and Technology, 42(2), 664-671. doi:10.1016/j.lwt.2008.07.010

Tsironi, T., Gogou, E., Velliou, E., \& Taoukis, P. S. (2008). Application and validation of the tti based chill chain management system smas (safety monitoring and assurance system) on shelf life optimization of vacuum packed chilled tuna. International Journal of Food Microbiology, 128(1, SI), 108-115. 5th International Conference on Predictive Modelling in Foods, Natl Tech Univ Athens, Athens, GREECE, SEP 1619, 2007. doi:10.1016/j.ijfoodmicro.2008. 07.025

Tsironi, T., Stamatiou, A., Giannoglou, M., Velliou, E., \& Taoukis, P. S. (2011). Predictive modelling and selection of time temperature integrators for monitoring the shelf life of modified atmosphere packed gilthead seabream fillets. LWT-Food Science and Technology, 44(4), 1156-1163. doi:10. 1016/j.lwt.2010.10.016 